\title{
A Hybrid Molecular Photoanode for Efficient Light Induced Water Oxidation
}

Received 00th January 20xx Accepted 00th January 20xx DOI: $10.1039 / \times 0 \times x 00000 x$ www.rsc.org/
Sergi Grau, $+^{\mathrm{a}}$ Serena Berardi, ${ }^{*}{ }^{\mathrm{b}}$ Alicia Moya, ${ }^{\mathrm{c}}$ Roc Matheu, ${ }^{\mathrm{a}}$ Vito Cristino, ${ }^{\mathrm{b}}$ Juan José Vilatela, ${ }^{\mathrm{c}}$ Carlo A. Bignozzi, ${ }^{b}$ Stefano Caramori, ${ }^{\text {b }}$ Carolina Gimbert-Suriñach, ${ }^{* a}$ Antoni Llobet*a

\section{Introduction}

The conversion of solar energy is on the focus of worldwide scientific research with the aim to turn into a more sustainable energy management of our society. While photovoltaic (PV) and solar thermal technologies are a reality with solar panels generating part of global energy production, the conversion of solar energy into clean fuels is still in a laboratory-scale stage. ${ }^{1}$ The latter strategy offers a solution to the mismatch between sunlight intermittence and energy needs by converting the sunlight energy into storable chemical bonds. One of the reasons that hinders the implementation of such technology is the difficulty to find an efficient light absorbing material coupled to active electrocatalysts, either connected through wires in a typical PV-electrochemical (PV-EC) configuration or via semiconductor-electrolyte interfaces. ${ }^{1-3}$ The system needs to effectively absorb light and produce long lived separated charges to facilitate fast electron and hole transfer to catalysts

\footnotetext{
a. Institute of Chemical Research of Catalonia (ICIQ), Barcelona Institute of Science and Technology (BIST), Avda. Països Catalans 16, 43007 Tarragona, Spain.

b. Dept. of Chemistry and Pharmaceutical Sciences, University of Ferrara, Via di Mortara 17, 44121, Ferrara, Italy.

c. IMDEA Materials Institute, C. Eric Kandel 2, 28906, Getafe, Madrid, Spain.

† These authors contributed equally to this work.

Electronic Supplementary Information (ESI) available: [details of any supplementary information available should be included here]. See DOI: 10.1039/x0xx00000x
}

in order to drive the desired chemical reactions. In this regard, the water oxidation reaction is one of the limiting process within such a complex system due to high demands needed for efficient catalysts, namely, a high thermodynamic potential and large kinetic complexity. Indeed the latter complexity is a consequence of the need to transfer four electrons and four protons from two water molecules together with the generation of an $0-0$ bond (Figure 1). ${ }^{4-6}$ For this reason, great efforts are devoted nowadays to the field of solar-to-fuel conversion, specifically to find highly performant electroanodes and photoanodes for the water oxidation reaction. ${ }^{2,7-9}$

Tungsten oxide $\left(\mathrm{WO}_{3}\right)$ and bismuth vanadate $\left(\mathrm{BiVO}_{4}\right)$ are two promising semiconductor materials with suitable band gap and valence band positon to carry out photoinduced water oxidation. ${ }^{7,8}$ In particular, $\mathrm{BiVO}_{4}$ has shown excellent photocurrent densities at potentials close to and even lower than the thermodynamic value. However, the performances of $\mathrm{BiVO}_{4}$ photoanodes are still far from its theoretical maximum capacities. ${ }^{7,8}$ This problem is associated with the slow charge carrier mobility as well as slow kinetics of the water oxidation 
reaction at the surface of the electrode. Four main strategies have been used to overcome these unfavorable phenomena: i) doping with metallic elements (particularly good results obtained with $\mathrm{W}$ and Mo), ${ }^{10}$ ii) tuning morphology and nanostructure of the material, ${ }^{10-12}$ iii) formation of heterojunctions with other semiconductors (e.g. $\left.\mathrm{WO}_{3}\right)^{13,14}$ or conductive materials (e.g. graphene) $)^{7,15}$ and iv) modifying the surface of the photoelectrode with suitable water oxidation catalysts (metal oxides or oxy(hydroxides)). ${ }^{16,17}$ While the first three strategies ( $i$-iii) are designed to enhance charge carrier mobility, charge separation and/or avoid recombination, the latter strategy (iv) is mainly addressed to reduce the high kinetic barrier associated with the water oxidation reaction. Interestingly, recent works point to the poor effect of metal oxide derivatives as water oxidation catalysts. ${ }^{17,18}$ Instead, they attribute the enhancement of the photocurrent densities to higher charge separation efficiency obtained with the presence of the metallic oxide deposited on the surface of the photoanode. ${ }^{17,18}$ These observations are in agreement with the intrinsic limited catalytic activity of metal oxides such as cobalt oxide that competes with the catalysis by the $\mathrm{BiVO}_{4}$ itself. In contrast to metal oxide catalysts, molecular water oxidation catalysts (WOC) have experienced a tremendous improvement in catalytic rates, achieving maximum turnover frequencies that are three to four orders of magnitude higher than the best water oxidation catalysts based on oxides. Indeed, molecular water oxidation catalysts outperform the naturally occurring Oxygen Evolving Complex in Photosystem II, responsible for oxygen release in the natural photosynthetic process in plants, by two orders of magnitude. ${ }^{5,6,19}$ More recently, strategies to anchor these molecular catalysts on electrode surfaces have been developed, maintaining the high catalytic activity observed in homogeneous conditions and in some cases even increasing their performance. ${ }^{20-22}$

In this work, we couple a $\mathrm{WO}_{3} / \mathrm{BiVO}_{4}$ photoanode with a highly active molecular WOC with the aim of enhancing the kinetics of the chemical reaction, minimizing recombination and oxide degradation, and thus improving the overall performance of the photoelectrode. A carbon nanotube fibre interlayer film between the photoactive material and the catalyst is used as highly conductive platform that facilitates the anchoring of the functionalized molecular WOC and allows fast charge transfer between the two key components (semiconductor and catalyst) of the photoelectrode (Figure 1).

\section{Results}

\section{Fabrication of the hybrid photoanode}

The multilayer architecture of the $\mathrm{WO}_{3} / \mathrm{BiVO}_{4}$ photoactive material used in this study is shown in Figure 1. It is made of three well defined layers, namely, a compact thin film of tungsten oxide $\left(\mathrm{WO}_{3(\mathrm{C})}\right)$, a mesoporous layer of the same material $\left(\mathrm{WO}_{3(\mathrm{P})}\right)^{23}$ and a top layer of porous $\mathrm{BiVO}_{4} .{ }^{16}$ The inner compact layer of $\mathrm{WO}_{3(\mathrm{C})}$ is essential for isolating the back FTO contact from the electrolyte solution, avoiding dark currents associated with shunt phenomena. This effect is clearly seen in

2 | J. Name., 2012, 00, 1-3

\section{$2 \mathrm{H}_{2} \mathrm{O}+$ hu Water Oxidation PhotoCatalysis $\mathrm{O}_{2}+4 \mathrm{H}^{+}+4 \mathrm{e}$}

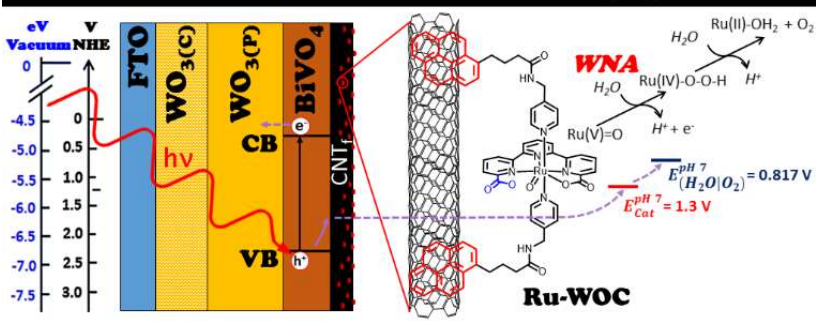

Figure 1. Hybrid photoanode design studied in this work. $\mathrm{WO}_{3(\mathrm{C})}$ = compact tungsten oxide film, $\mathrm{WO}_{3}=$ mesoporous tungsten oxide layer, $\mathrm{Ru}-\mathrm{WOC}=$ molecular ruthenium water oxidation catalyst with pyrene groups in red and dangling carboxylate group in blue, WNA = water nucleophilic attack, $E$ (cat) = oxidation potential of catalyst to give the $\mathrm{Ru}(\mathrm{V})$-oxo active species, $E\left(\mathrm{H}_{2} \mathrm{O} / \mathrm{O}_{2}\right)=$ thermodynamic potential of water oxidation at $\mathrm{pH} 7$.

Figure S5, which shows that in the absence of light the electrode $\mathrm{WO}_{3(\mathrm{C})} / \mathrm{WO}_{3(\mathrm{P})} / \mathrm{BiVO}_{4}$ does not show any current in the whole potential range while the electrode that lacks the $\mathrm{WO}_{3}$ compact underlayer $\left(\mathrm{WO}_{3(\mathrm{P})} / \mathrm{BiVO}_{4}\right)$ shows significant dark currents from $0.75 \mathrm{~V}$ vs NHE. On the other hand, the heterostructured $\mathrm{WO}_{3} / \mathrm{BiVO}_{4}$ porous material has shown improved performance as compared to bare $\mathrm{BiVO}_{4}$ photoanodes. ${ }^{13,14}$ This improvement is attributed to the good band alignment and synergistic effects between the two semiconductors, leading to higher charge separation efficiencies. ${ }^{14}$ Detailed structural, electrochemical and optical characterization of the photoanodes used in this work is given in Figures S1-S5 in the supporting information.

The water oxidation catalyst, Ru-WOC in Figure 1, was selected for its high activity both in homogeneous and in heterogeneous conditions. 19,20,22 This catalyst is known to operate via an electrophilic $\mathrm{Ru}(\mathrm{V})$-oxo species that suffers a water nucleophilic attack (WNA) by a water molecule forming an hydroperoxo key derivative with a newly formed O-O bond. The high catalytic rate that characterizes this catalyst is attributed to the role of the dangling carboxylate group assisting the $\mathrm{O}-\mathrm{O}$ bond formation step (Figure 1, blue moiety of the Ru-WOC complex). ${ }^{24}$ Several reports describe the direct attachment of molecular catalysts on semiconducting materials, usually by using phosphonates or carboxylate groups..$^{25,26,27}$ In the present case, when the Ru-WOC is attached to the $\mathrm{WO}_{3} / \mathrm{BiVO}_{4}$ photoanode, no improvement of the performance of the electrode is observed. This result is due to deactivation of the dangling carboxylate group, which interacts directly with the metal oxide hindering its proper activation. ${ }^{27}$ This can be avoided by using a conductive support that isolates the catalyst from the photoelectrode surface. The support should guarantee fast charge transfer from the semiconductor to the catalyst, while maintaining the ruthenium catalytic centre unaltered. In this regard, carbon nanostructures such as graphene, single or multiwalled carbon nanotubes are good candidates for their unique properties including high surface area, high thermal and electrical conductivity as well as chemical inertness. In particular, carbon nanotube fibres $\left(\mathrm{CNT}_{f}\right)$ are excellent 
conductive platforms. They are macroscopic arrays of CNTs combining surface area around $250 \mathrm{~m}^{2} / \mathrm{g}$, electrical conductivity of $3.5 \times 10^{5} \mathrm{~S} / \mathrm{m}$, high electrochemical stability ${ }^{28}$ and the possibility to produce them in a kilometer/day scale, ${ }^{29}$ for example as free-form electrodes. In this direction, the hybrid molecular photoanode device is prepared following a new strategy; an approximately $1 \times 1 \mathrm{~cm}^{2}$ of $\mathrm{WO}_{3} / \mathrm{BiVO}_{4}$ photoanode is covered with an approximately $0.9 \times 0.9 \mathrm{~cm}^{2}$ of a $\mathrm{CNT}_{\mathrm{f}}$ film with a thickness of around $5 \mu \mathrm{m}$, estimated based on fibre linear density, winding rate and spinning time. ${ }^{29}$ Next, the resulting $\mathrm{WO}_{3} / \mathrm{BiVO}_{4} / \mathrm{CNT}_{\mathrm{f}}$ is soaked in a $1 \mathrm{mM}$ methanolic solution of the Ru-WOC precursor overnight to allow for the chemical attachment of the ruthenium complex on the surface of the electrode via pi-pi interactions of the pyrene groups of the complex and the graphitic structure of the $\mathrm{CNT}_{\mathrm{f}}$ (Figure 1). After this treatment, the electrodes are rinsed with clean methanol to make sure that excess of the homogeneous catalyst is removed and carefully dried with an air flow. In order to estimate the loading of the catalyst on the surface of the electrode, analogous experiments with non-photoactive $\mathrm{ITO} / \mathrm{CNT}_{f}$ electrodes were done. Analysis of the current underneath the $\mathrm{Ru}(\mathrm{III} / \mathrm{II})$ wave in the cyclic voltammetry (CV) of the resulting ITO/CNT $/$ Ru-WOC electrodes allow us to calculate the amount of catalyst precursor on the $\mathrm{CNT}_{\mathrm{f}}$ film, giving values up to $\Gamma=15 \mathrm{nmol} / \mathrm{cm}^{2}$, comparable to those observed in previous studies that used multiwalled carbon nanotubes (Figure S9).20,22 This confirms that the free-standing format and high surface area of $\mathrm{CNT}_{\mathrm{f}}$ makes them an attractive conducting support in heterogeneous catalysis.

\section{Photoelectrochemical performance}

The photoelectrochemical performance of the photoanodes was tested in a typical one-compartment three-electrodes photoelectrochemical cell, as described in detail in the supporting information. The $\mathrm{CNT}_{\mathrm{f}}$ are extremely black layers that completely block incoming light, therefore all the photoelectrochemical results presented in this study are based on back illumination of the photoelectrodes. The photoelectrochemical behaviour of the bare $\mathrm{WO}_{3} / \mathrm{BiVO}_{4}$ photoanodes improves over consecutive linear sweep voltammetry (LSV) experiments as shown in Figure S8. Thus, all electrodes were exposed to an electrochemical pre-treatment until a constant photocurrent response was achieved previous to any modification (usually 3-5 LSV cycles).

Figure 2 shows the chopped light LSV performance of a $\mathrm{WO}_{3} / \mathrm{BiVO}_{4}$ photoanode and that of a $\mathrm{WO}_{3} / \mathrm{BiVO}_{4} / \mathrm{CNT}$ analogue in $\mathrm{pH} 7$ buffered solution, showing a significant decrease of the photocurrent when the $\mathrm{CNT}_{f}$ is present (compare red and black traces). This result is in agreement with the $\mathrm{CNT}_{f}$ film blocking the $\mathrm{BiVO}_{4}$ active centres responsible for the water oxidation catalysis. Thus, while the $\mathrm{CNT}_{f}$ film is highly conductive, it is unable to perform the chemical reaction, in other words it does not act as water oxidation catalysts under these conditions. On the other hand, the presence of the RuWOC on the surface of the electrode significantly improves the performance of the photocurrent, particularly in the range of

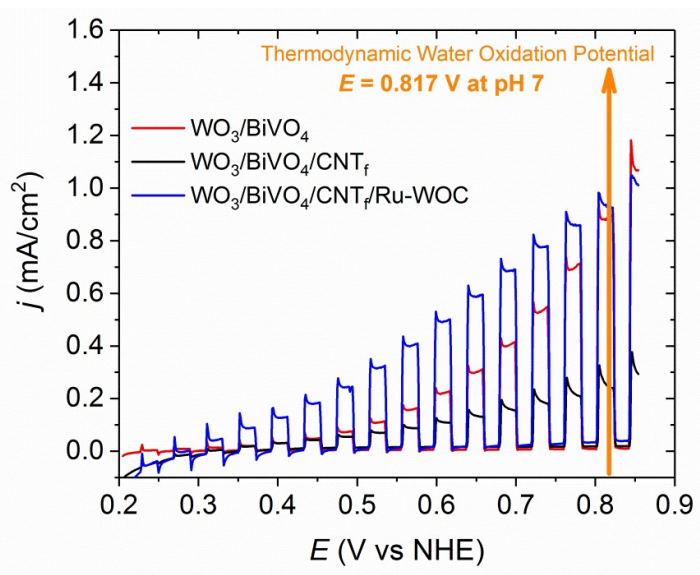

Figure 2. IR drop compensated chopped light LSV $(5 \mathrm{mV} / \mathrm{s})$ of different photoanodes in $\mathrm{pH} 7$ phosphate buffer. $\mathrm{WO}_{3} / \mathrm{BiVO}_{4}$ (red), $\mathrm{WO}_{3} / \mathrm{BiVO}_{4} / \mathrm{CNT}_{\mathrm{f}}$ (black) and $\mathrm{WO}_{3} / \mathrm{BiVO}_{4} / \mathrm{CNT}_{\mathrm{f}} / \mathrm{Ru}-\mathrm{WOC}$ (blue).

$0.3 \mathrm{~V}$ to $0.8 \mathrm{~V}$ vs NHE (compare blue trace with black and red traces in Figure 2). The improvement goes from $0.05 \mathrm{~mA} / \mathrm{cm}^{2}$ at $0.3 \mathrm{~V}$ up to $0.29 \mathrm{~mA} / \mathrm{cm}^{2}$ at $0.7 \mathrm{~V}$ vs NHE. In order to make sure that this enhancement is due to the catalyst and not to the methanolic solution treatment during catalyst deposition, we did analogous blank tests. Specifically, $\mathrm{WO}_{3} / \mathrm{BiVO}_{4} / \mathrm{CNT}_{\mathrm{f}}$ electrodes were soaked in clean methanol overnight and subsequently dried. The resulting treated electrodes did not show a significant improvement of the performance, confirming that the increased photocurrent observed in Figure 2 is due to the presence of the catalyst (Figure S10).

Bulk electrolysis experiments show that the full electrode $\mathrm{WO}_{3} / \mathrm{BiVO}_{4} / \mathrm{CNT}_{\mathrm{f}} / \mathrm{Ru}$-WOC outperforms the bare $\mathrm{WO}_{3} / \mathrm{BiVO}_{4}$ electrode (Figure 3, blue and red traces, respectively). We attribute this photocurrent enhancement to the higher catalytic

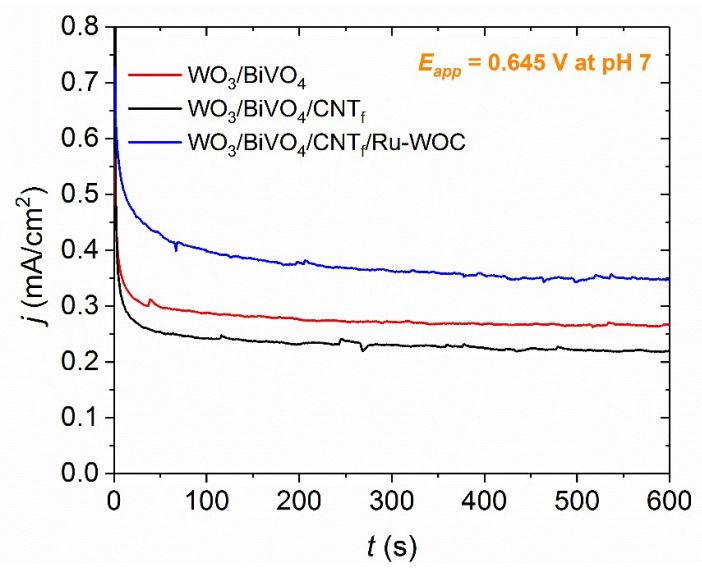

Figure 3. Bulk electrolysis experiment at applied potential $E_{\mathrm{app}}=$ 0.645 vs NHE in $\mathrm{pH} 7$ phosphate buffer, $I R$ drop was not compensated. $\mathrm{WO}_{3} / \mathrm{BiVO}_{4}$ (red), $\mathrm{WO}_{3} / \mathrm{BiVO}_{4} / \mathrm{CNT}_{\mathrm{f}}$ (black) and $\mathrm{WO}_{3} / \mathrm{BiVO}_{4} / \mathrm{CNT}_{\mathrm{f}} / \mathrm{Ru}$-WOC (blue).

activity of Ru-WOC compared to $\mathrm{BiVO}_{4}$. The integrity of the molecular water oxidation catalyst after bulk electrolysis 
experiments was tested by carefully removing the $\mathrm{CNT}_{\mathrm{f}} / \mathrm{Ru}$ WOC film from the surface of the $\mathrm{WO}_{3} / \mathrm{BiVO}_{4}$ electrode and placing it on a clean ITO electrode. As depicted in Figure S9, the fingerprint of the ruthenium complex is still intact on the film.

Oxygen detection experiments were done to prove that the enhanced photocurrent obtained with the $\mathrm{WO}_{3} / \mathrm{BiVO}_{4} / \mathrm{CNT}_{\mathrm{f}} / \mathrm{Ru}-\mathrm{WOC}$ electrode is due to water oxidation catalysis. An adapted Generator-Collector device was used, which is inspired by previously reported procedures that have been built for related photoelectrochemical systems (Figure 4 and Figures S11-S13 in the supporting information). ${ }^{30,31}$ In particular, a slow scan rate LSV on the desired photoelectrode (Generator) is performed while a controlled potential electrolysis in a closely positioned FTO electrode (Collector) is simultaneously run. In the Collector electrode, the generated oxygen is reduced after diffusion through the solution from the Generator electrode. Thus, the current observed in the controlled potential electrolysis experiment is a measure of the evolved gas due to the water oxidation reaction on the photoelectrode. This method allows us to measure the oxygen gas in situ and to control at what potential the chemical reactions starts. As shown in Figure 4 and Figure S12, the oxygen evolution reaction for the full hybrid electrode $\mathrm{WO}_{3} / \mathrm{BiVO}_{4} / \mathrm{CNT}_{\mathrm{f}} / \mathrm{Ru}-\mathrm{WOC}$ starts at a potential $140 \mathrm{mV}$ lower than that of the bare electrode $\mathrm{WO}_{3} / \mathrm{BiVO}_{4}$ (ca. $0.41 \mathrm{~V}$ for the former and $0.55 \mathrm{~V}$ for the latter). The faradaic efficiency calculated for these experiments are $94 \%$ for $\mathrm{WO}_{3} / \mathrm{BiVO}_{4} / \mathrm{CNT}_{\mathrm{f}} / \mathrm{Ru}-\mathrm{WOC}$ and $97 \%$ for $\mathrm{WO}_{3} / \mathrm{BiVO}_{4}$ (Figure S13). The delay in detecting the oxygen is attributed to the diffusion process of the oxygen gas from the generator electrode to the collector electrode $(0.3 \mathrm{~V}$ from LSV in Figure 2 vs $0.41 \mathrm{~V}$ from G$\mathrm{C}$ method in Figure 4 and Figure S12).

\section{Electrochemical impedance spectroscopy analysis}

In order to get further insights into the role of the different interfaces involved in the photocurrent generation, electrochemical impedance spectroscopy (EIS) experiments under illumination and different applied biases were carried out. The results have been fitted using a circuital model adapted from reported works (Figure 5A). ${ }^{14,32,33}$ Briefly, it consists of a serial resistance of the electrochemical cell $\left(R_{1}\right)$, in series with a $\mathrm{R}_{2}-\mathrm{CPE}_{2}$ mesh and an extended element (TL). The latter is commonly used to represent the transmission line of mesoporous films $\left(\mathrm{WO}_{3} / \mathrm{BiVO}_{4}\right.$ in our case), through which the photogenerated carriers travel overcoming the transport resistance $\left(R_{t r}\right)$ between the fused nanoparticles. The approximation of a negligible capacitance contribution between the particles is generally used. Furthermore, the model includes a resistive contribution $\left(R_{c t}\right)$ due to the charge carrier recombination (which eventually influences the charge transfer to the electrolyte), as well as a capacitive contribution accounting for the accumulation of photogenerated charges in the film ( $\left.C P E_{\text {film }}\right)$. On the other hand, the $\mathrm{R}_{2}-\mathrm{CPE}_{2}$ mesh has been introduced to take into account the $\mathrm{FTO} / \mathrm{WO}_{3}$ interface or the $\mathrm{CNT}_{\mathrm{f}} /$ electrolyte interface when the $\mathrm{CNT}_{\mathrm{f}}$ are present.

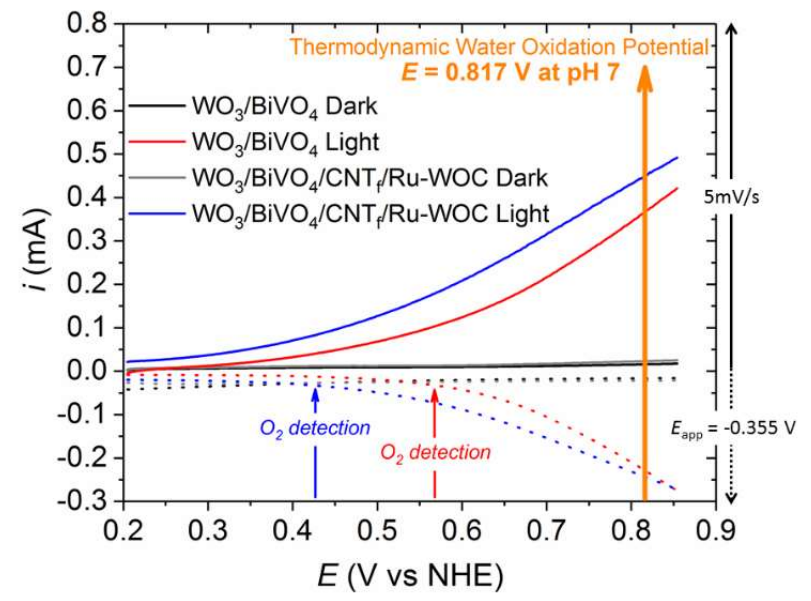

Figure 4. Oxygen gas detection experiments using an adapted Generator-Collector method performed in $\mathrm{pH} 7 .{ }^{30,31}$ Solid lines correspond to LSV $(5 \mathrm{mV} / \mathrm{s})$ performed on the photoanode electrode (Generator). The dotted lines correspond to the in situ current observed on the Collector electrode due to $\mathrm{O}_{2}$ reduction (Controlled Potential Electrolysis at $E_{\text {app }}=-0.355 \mathrm{~V}$ vs $\mathrm{NHE}$, see details in the supporting information). $\mathrm{WO}_{3} / \mathrm{BiVO}_{4}$ in the dark (black), $\mathrm{WO}_{3} / \mathrm{BiVO}_{4}$ under 1 sun illumination (red), $\mathrm{WO}_{3} / \mathrm{BiVO}_{4} / \mathrm{CNT}_{\mathrm{f}} / \mathrm{Ru}-\mathrm{WOC}$ in the dark (grey) and $\mathrm{WO}_{3} / \mathrm{BiVO}_{4} / \mathrm{CNT}_{\mathrm{f}} / \mathrm{Ru}-\mathrm{WOC}$ under 1 sun illumination (blue).

The experimental Nyquist plots of the different photoanodes, together with the corresponding fittings, are reported in Figure $5 \mathrm{~B}$ and Figure S14, evidencing the good agreement provided by the selected circuital model. The major contribution of the total resistance is given by $R_{c t}$, which follows the same dependence from the applied bias of the inverse of the differential resistance (Figure S15). The exact values, obtained for the different resistive and capacitive contributions, are reported in Table S1 and Table S2, respectively.

In the model, $R_{c t}$ represents the recombination through the nanostructured film, and therefore its contribution is expected to decrease for systems that can effectively transfer charge to the electrolyte and perform fast water oxidation catalysis. Figure $5 \mathrm{C}$ reports the bias dependence of the logarithm of $R_{c t}$ and gives a quantification of this recombination phenomenon. The presence of the Ru-WOC coupled to the $\mathrm{CNT}_{f}$ reduces the $R_{c t}$ value of the corresponding photoanode by $c a$. three times in the whole range of potential (compare blue and black traces). The charge transfer rate to the aqueous electrolyte is indeed expected to be lower for the $\mathrm{WO}_{3} / \mathrm{BiVO}_{4} / \mathrm{CNT}_{\mathrm{f}}$ electrodes without the molecular catalyst, due to the hydrophobicity of the $\mathrm{CNT}_{f}$ layer and the blockage of the active catalytic sites of $\mathrm{BiVO}_{4}$. On the other hand, with regard to the bare $\mathrm{WO}_{3} / \mathrm{BiVO}_{4}$ electrode, the enhancement of the charge transfer by the RuWOC is only improved at low potentials, as evidenced by the crossing point of the blue and red traces in Figure $5 \mathrm{C}$. Furthermore, it is worth noting that the $\mathrm{WO}_{3} / \mathrm{BiVO}_{4}$ electrode shows a bell-shaped behaviour (red trace in Figure $5 \mathrm{C}$ ) with a minimum around $0.69 \mathrm{~V}$ vs NHE, i.e. at the inflection point of the LSV curve of the photoelectrode (Figure S14). With regard 
A
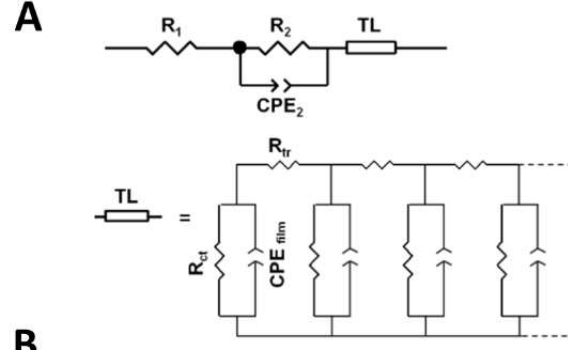

B

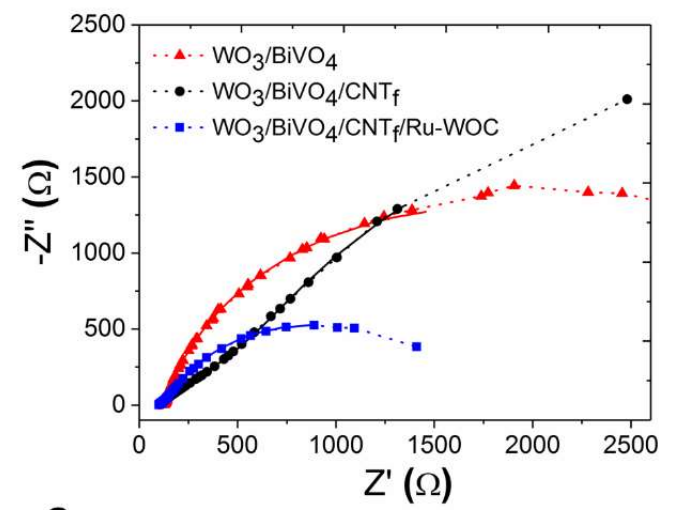

C

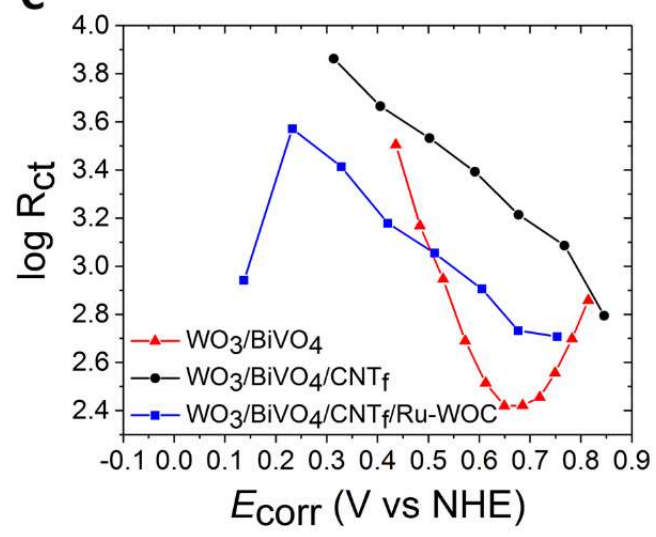

Figure 5. A, Equivalent circuit used to fit the EIS data of the photoanodes. B, complex plane Nyquist plots for the different electrodes measured under 1 sun illumination in $\mathrm{pH} 7$ phosphate buffer at $0.440 \mathrm{~V}$ vs NHE. The corresponding fits are also reported as thick solid lines. $C, \log R_{c t} v s$ potential. Legend code: $\quad \mathrm{WO}_{3} / \mathrm{BiVO}_{4}$ (red), $\quad \mathrm{WO}_{3} / \mathrm{BiVO}_{4} / \mathrm{CNT}_{\mathrm{f}}$ (black) and $\mathrm{WO}_{3} / \mathrm{BiVO}_{4} / \mathrm{CNT}_{\mathrm{f}} / \mathrm{Ru}$-WOC (blue).

to other resistive contributions, the resistance that we associate with the inert $\mathrm{FTO} / \mathrm{WO}_{3}$ interface for bare $\mathrm{WO}_{3} / \mathrm{BiVO}_{4}$ is $<15 \Omega$ and it is substantially independent on the applied bias, as expected when the interface is not directly involved in the photocurrent generation mechanism. ${ }^{14}$ On the other hand, for the $\mathrm{WO}_{3} / \mathrm{BiVO}_{4} / \mathrm{CNT}_{\mathrm{f}}$ electrodes, the $\mathrm{R}_{2}$ values are much higher (in the range of 330-625 $\Omega$ ), as well as bias-dependent. Thus, in this case, the $\mathrm{R}_{2}-\mathrm{CPE}_{2}$ mesh has been assigned to the $\mathrm{CNT}_{\mathrm{f}} /$ electrolyte interface, whose higher resistive contribution covers the one due to the $\mathrm{FTO} / \mathrm{WO}_{3}$ interface, that was considered in the first place. This characteristic can be seen in the Nyquist plots, resulting in an additional arc for the $\mathrm{WO}_{3} / \mathrm{BiVO}_{4} / \mathrm{CNT}_{\mathrm{f}}$ electrode (Figure $5 \mathrm{~B}$, black trace). When the latter is coupled with the Ru-WOC, the $R_{2}$ values (assigned by analogy to the functionalized $\mathrm{CNT}_{\mathrm{f}} /$ electrolyte interface decrease by at least one order of magnitude $(<25 \Omega)$ with respect to the non-catalytic $\mathrm{WO}_{3} / \mathrm{BiVO}_{4} / \mathrm{CNT}_{\mathrm{f}}$, as expected from the improved surface kinetics in the presence of the catalyst, which also induces wetting of the porous $\mathrm{CNT}_{f}$ layer. Furthermore, the $R_{2}$ values are bias dependent for $\mathrm{WO}_{3} / \mathrm{BiVO}_{4} / \mathrm{CNT}_{\mathrm{f}} / \mathrm{Ru}-\mathrm{WOC}$, with a minimum at $0.64 \mathrm{~V}$ vs NHE, close to the inflection point of the LSV curve (Figure S14 and $\mathrm{S} 15 \mathrm{E})$. More information on the nanofibres/electrolyte interface can be extracted from the capacitance values given by $\mathrm{CPE}_{2}$, which follows a similar potential dependence for both $\mathrm{WO}_{3} / \mathrm{BiVO}_{4} / \mathrm{CNT}_{\mathrm{f}}$ and $\mathrm{WO}_{3} / \mathrm{BiVO}_{4} / \mathrm{CNT}_{\mathrm{f}} / \mathrm{Ru}$-WOC (Figure S16). These results support the hypothesis of reduced electron recombination with surface trapped holes (that may translate into $\mathrm{WO}_{3} / \mathrm{BiVO}_{4}$ defects, oxidized $\mathrm{CNT}_{\mathrm{f}}$ or oxidized catalyst) as the potential increases.

In the case of the $\mathrm{WO}_{3} / \mathrm{BiVO}_{4}$ electrodes, the logarithm of the capacitance associated to the charge accumulation in the film $\left(C P E_{\text {film }}\right)$ displays a linear dependence on the applied bias, as soon as the surface states have been emptied by the voltage, at approximately $0.54 \mathrm{~V}$ vs NHE (Figure S17). This behaviour is typical of a chemical capacitor, as expected for this kind of electrodes. ${ }^{34} \mathrm{~A}$ higher $\mathrm{CPE}_{\text {film }}$ value has been observed for $\mathrm{WO}_{3} / \mathrm{BiVO}_{4} / \mathrm{CNT}_{\mathrm{f}} / \mathrm{Ru}$-WOC photoanodes, confirming that in the presence of the catalyst a higher charge can be accumulated and then transported to the electrolyte. It is worth noting that the higher $\mathrm{CPE}_{\text {film }}$ values for $\mathrm{WO}_{3} / \mathrm{BiVO}_{4} / \mathrm{CNT}_{\mathrm{f}} / \mathrm{Ru}-\mathrm{WOC}$ correspond to lower $R_{\mathrm{ct}}$ values in the $0.15-0.50 \mathrm{~V}$ vs NHE range, i.e. where the photocurrent response is anticipated with respect to the bare $\mathrm{WO}_{3} / \mathrm{BiVO}_{4}$ electrode (compare red and blue traces in Figure $5 \mathrm{C}$ and Figure S17). Furthermore, we observe that CPE film follows same bias dependence for $\mathrm{WO}_{3} / \mathrm{BiVO}_{4} / \mathrm{CNT}_{\mathrm{f}} / \mathrm{Ru}-\mathrm{WOC}$ and $\mathrm{WO}_{3} / \mathrm{BiVO}_{4}$ electrodes at high potentials ( $>0.59 \mathrm{~V}$ vs NHE), while for lower values it results essentially constant, as also observed in the case of $\mathrm{WO}_{3} / \mathrm{BiVO}_{4} / \mathrm{CNT}_{\mathrm{f}}$. The higher $\mathrm{CPE}_{\text {film }}$ values obtained in the latter case suggest a significant charge accumulation on the $\mathrm{CNT}_{\mathrm{f}}$ layer (or on $\mathrm{BiVO}_{4}$ states covered by $\mathrm{CNT}_{\mathrm{f}}$ ), which can be followed by a good charge transfer to the electrolyte only when the WOC is coupled to them.

\section{Discussion}

Figure 1 shows the potential values required to oxidize the molecular catalyst attached on the surface of the $\mathrm{WO}_{3} / \mathrm{BiVO}_{4} / \mathrm{CNT}_{\mathrm{f}} / \mathrm{Ru}-\mathrm{WOC}$ photoanode and generate the $\mathrm{Ru}(\mathrm{V})=\mathrm{O}$ active species $\left(E_{(\mathrm{RuV} / \mathrm{IV})}=1.3 \mathrm{~V}\right.$ vs $\left.\mathrm{NHE}\right)$. This potential should be easily overcome by the oxidative power of the low $\mathrm{BiVO}_{4}$ valence band upon illumination $\left(E_{\mathrm{VB}, \mathrm{pH}} 7=2.2-2.4 \mathrm{~V}\right.$ vs $\mathrm{NHE}){ }^{35}$ Once the $\mathrm{Ru}(\mathrm{V})=\mathrm{O}$ species is formed, the water oxidation catalytic process is triggered and occurs at a maximum rate of almost 8000 cycles per second. ${ }^{19,20}$ Thus, upon illumination, the electrode $\mathrm{WO}_{3} / \mathrm{BiVO}_{4} / \mathrm{CNT}_{\mathrm{f}} / \mathrm{Ru}-\mathrm{WOC}$ 
should be able to perform oxygen evolution catalysis. Figure 2 proves that indeed the $\mathrm{WO}_{3} / \mathrm{BiVO}_{4} / \mathrm{CNT}_{\mathrm{f}} / \mathrm{Ru}-\mathrm{WOC}$ shows enhanced photocurrent at potentials lower than the $\mathrm{WO}_{3} / \mathrm{BiVO}_{4}$ and $\mathrm{WO}_{3} / \mathrm{BiVO}_{4} / \mathrm{CNT}_{\mathrm{f}}$ electrodes (compare blue with red and black traces). Bulk electrolysis and oxygen measurement experiments confirmed that the enhanced photocurrent is sustained over several minutes and that the current is due to oxygen gas formation (Figure 3 and 4). More importantly, the oxygen gas is detected at approximately $0.41 \mathrm{~V}$ vs $\mathrm{NHE}$ using the catalyst modified electrode $\mathrm{WO}_{3} / \mathrm{BiVO}_{4} / \mathrm{CNT}_{\mathrm{f}} / \mathrm{Ru}-\mathrm{WOC}, 140 \mathrm{mV}$ before the bare photoanode $\mathrm{WO}_{3} / \mathrm{BiVO}_{4}$ (Figure 4 and Figure S12) with faradaic efficiencies close to $100 \%$. These results not only prove that the Ru-WOC performs the reaction but also, that the charge is efficiently transferred all the way through the multilayered architecture of the photoanode, i.e., from the inner semiconductor, to the CNT fibres and finally to the catalyst. In this regard, the CNT fibres form an effective and stable interlayer with excellent charge transfer abilities. In addition, their work function above the conduction band of $\mathrm{BiVO}_{4}$ might contribute to charge separation by preventing recombination phenomena. ${ }^{36}$ Also, the $\mathrm{CNT}_{\mathrm{f}}$ layer constitute an excellent platform for the easy anchoring of molecular catalysts.

EIS analysis allowed us to differentiate two potential ranges in which the $\mathrm{CNT}_{\mathrm{f}} / \mathrm{Ru}$-WOC interface have distinct influence on the overall catalytic performance. At high potentials, although the charge accumulation capacity of the complete photoanode $\mathrm{WO}_{3} / \mathrm{BiVO}_{4} / \mathrm{CNT}_{\mathrm{f}} / \mathrm{Ru}-\mathrm{WOC}$ is higher than that of simple $\mathrm{WO}_{3} / \mathrm{BiVO}_{4}$, the recombination is also higher, resulting in similar performance (Figures $5 \mathrm{C}$ and Figure $\mathrm{S} 17, E>0.5 \mathrm{~V}$ vs NHE). At this potential range, the water oxidation catalysis by the RuWOC starts competing with the catalysis by the $\mathrm{BiVO}_{4}$ active centres of the bare $\mathrm{WO}_{3} / \mathrm{BiVO}_{4}$ electrode, that are available in higher quantities in the absence of carbon nanotube fibres. On the other hand, at low potentials the full electrode $\mathrm{WO}_{3} / \mathrm{BiVO}_{4} / \mathrm{CNT}_{\mathrm{f}} / \mathrm{Ru}-\mathrm{WOC}$ outperforms the $\mathrm{WO}_{3} / \mathrm{BiVO}_{4}$ photoanode, as a result of higher charge accumulation capacity and lower recombination phenomena (Figure $5 \mathrm{C}$ and Figure $\mathrm{S} 17, E<0.5 \mathrm{~V}$ vs NHE). This is particularly remarkable at the 0.3$0.5 \mathrm{~V}$ vs $\mathrm{NHE}$ range where the $\mathrm{WO}_{3} / \mathrm{BiVO}_{4}$ photoanode has practically no activity (Figure 1). This is a consequence of the high kinetic barrier of the water oxidation catalysis at $\mathrm{BiVO}_{4}$ catalytic centres, which require higher potential to perform the reaction and avoid recombination phenomena. In sharp contrast, the specially designed Ru-WOC is able to perform the catalytic reaction at a potential as low as $0.3 \mathrm{~V}$ vs NHE, that is, ca. $300 \mathrm{mV}$ higher than the semiconductor capacities ( $E=-0.05$ $\mathrm{V}$ vs NHE, Figures $\mathrm{S} 5$ ). This value is close to those obtained for the best $\mathrm{BiVO}_{4}$ based photoanodes described to date with onset potentials for the water oxidation catalysis in the range of -0.2 $\mathrm{V}$ to $0.2 \mathrm{~V}$ vs NHE. Among them, the best performing examples contain metal oxides (ruthenium, iron, cobalt or nickel) as water oxidation catalyst on the surface of the photoelectrode. ${ }^{11,12,17,18,37-39}$ Only limited examples of photoanodes modified with molecular catalysts have been reported with less efficiency than that of the photoanode $\mathrm{WO}_{3} / \mathrm{BiVO}_{4} / \mathrm{CNT}_{\mathrm{f}} / \mathrm{Ru}-\mathrm{WOC}$ reported in this work. ${ }^{40,41,42}$

Importantly, the photoelectrode reported here can perform the reaction $510 \mathrm{mV}$ below the thermodynamic potential of the water oxidation reaction at $\mathrm{pH} 7$, allowing for the overlap with state of the art photocathodes for the overall unassisted water splitting reaction. ${ }^{37,39}$ This work highlights the promising role of robust and fast true molecular water oxidation catalysts on enhancing photoanode performance.

\section{Summary and conclusions}

The preparation of a multilayer heterostructured $\mathrm{WO}_{3} / \mathrm{BiVO}_{4}$ photoanode containing two layers of $\mathrm{WO}_{3}$ (compact and mesoporous) and a porous $\mathrm{BiVO}_{4}$ film is described. The resulting photoactive material is covered by a highly conductive carbon nanotube fibre $\left(\mathrm{CNT}_{f}\right)$ that is able to accumulate charge but unable to perform the water oxidation reaction. Finally, the surface of the $\mathrm{CNT}_{f}$ is functionalized with a molecular catalyst precursor (Ru-WOC) modified with pyrene groups forming pi-pi stacking bonds. The Ru-WOC takes the charge accumulated on the $\mathrm{CNT}_{f}$ and rapidly transfers it to the solution by performing the water oxidation reaction. The system works at low potentials, where the bare $\mathrm{WO}_{3} / \mathrm{BiVO}_{4}$ is not active at all for the oxygen evolution reaction. However, at high potentials, the beneficial influence of the $\mathrm{CNT}_{\mathrm{f}} / \mathrm{Ru}$-WOC interfaces is not sufficient to overcome the good performance of the bare $\mathrm{WO}_{3} / \mathrm{BiVO}_{4}$. All these results have been rationalized by means of EIS experiments that prove the advantage of using a highly active molecular catalyst to trigger the water oxidation reaction all the way down to $510 \mathrm{mV}$ below the thermodynamic potential of the reaction. Further improvements on the current molecular based photoanode can be focused on increasing the catalyst loading that should lead to enhanced current density at low potentials.

\section{Conflicts of interest}

There are no conflicts to declare.

\section{Acknowledgements}

MINECO and FEDER (CTQ2016-80058-R, CTQ2015-73028-EXP, SEV 2013-0319, ENE2016-82025-REDT, CTQ2016-81923-REDC), and AGAUR (2017-SGR-1631) are gratefully acknowledged for financial support. The project leading to this application has received funding from the European Union's Horizon 2020 research and innovation programmes under the ERC-STG 678565 and the Marie Skłodowska-Curie Grant Agreement No 705723. Dr. Marcel Risch is gratefully acknowledged for providing and helping with experimental set-up.

\section{Notes and references}

1.

2. K. Sivula and R. van de Krol, Nat. Rev. Mater., 2016, 1, 15010. 
3. J. H. Montoya, L. C. Seitz, P. Chakthranont, A. Vojvodic, T. F. Jaramillo and J. K. Nørskov, Nat. Mater., 2016, 16, 70.

4. X. Sala, I. Romero, M. Rodríguez, L. Escriche and A. Llobet, Angew. Chem. Int. Ed., 2009, 48, 2842.

5. S. Berardi, S. Drouet, L. Francàs, C. Gimbert-Suriñach, M. Guttentag, C. Richmond, T. Stoll and A. Llobet, Chem. Soc. Rev., 2014, 43, 7501.

6. P. Garrido-Barros, C. Gimbert-Suriñach, R. Matheu, X. Sala and A. Llobet, Chem. Soc. Rev., 2017, 46, 6088.

7. H. L. Tan, R. Amal and Y. H. Ng, J. Mater. Chem. A, 2017, 5, 16498.

8. S. S. M. Bhat and H. W. Jang, ChemSusChem, 2017, 10, 3001.

9. C. C. L. McCrory, S. Jung, I. M. Ferrer, S. M. Chatman, J. C. Peters and T. F. Jaramillo, J. Am. Chem. Soc., 2015, 137, 4347.

$10 . \quad$ Z.-F. Huang, L. Pan, J.-J. Zou, X. Zhang and L. Wang, Nanoscale, 2014, 6, 14044.

11. T. W. Kim and K.-S. Choi, Science, 2014, 343, 990.

12. Y. Kuang, Q. Jia, H. Nishiyama, T. Yamada, A. Kudo and K. Domen, Adv. En. Mat., 2016, 6, 1501645.

13. S. J. Hong, S. Lee, J. S. Jang and J. S. Lee, Energy Environ. Sci., 2011, 4, 1781.

14. X. Shi, I. Herraiz-Cardona, L. Bertoluzzi, P. Lopez-Varo, J. Bisquert, J. H. Park and S. Gimenez, Phys. Chem. Chem. Phys., 2016, 18, 9255.

15. M.-Q. Yang, N. Zhang, M. Pagliaro and Y.-J. Xu, Chem. Soc. Rev., 2014, 43, 8240.

16. J. A. Seabold and K.-S. Choi, J. Am. Chem. Soc., 2012, 134, 2186.

17. Y. Ma, A. Kafizas, S. R. Pendlebury, F. Le Formal and J. R. Durrant, Adv. Funct. Mater., 2016, 26, 4951.

18. C. Zachaus, F. F. Abdi, L. M. Peter and R. van de Krol, Chem. Sci., 2017, 8, 3712.

19. R. Matheu, M. Z. Ertem, J. Benet-Buchholz, E. Coronado, V. S. Batista, X. Sala and A. Llobet, J. Am. Chem. Soc., 2015, 137, 10786.

20. J. Creus, R. Matheu, I. Peñafiel, D. Moonshiram, P. Blondeau, J. Benet-Buchholz, J. García-Antón, X. Sala, C. Godard and A. Llobet, Angew. Chem. Int. Ed., 2016, 55, 15382.

21. P. Garrido-Barros, C. Gimbert-Suriñach, D. Moonshiram, A. Picón, P. Monge, V. S. Batista and A. Llobet, J. Am. Chem. Soc., 2017, 139, 12907.

22. R. Matheu, I. A. Moreno-Hernandez, X. Sala, H. B. Gray, B. S. Brunschwig, A. Llobet and N. S. Lewis, J. Am. Chem. Soc., 2017, 139, 11345.

23. V. Cristino, S. Marinello, A. Molinari, S. Caramori, S. Carli, R. Boaretto, R. Argazzi, L. Meda and C. A. Bignozzi, J. Mater. Chem. A, 2016, 4, 2995.

24. R. Matheu, M. Z. Ertem, C. Gimbert-Suriñach, J. BenetBuchholz, X. Sala and A. Llobet, ACS Catal., 2017, 7, 6525.

25. M. K. Brennaman, R. J. Dillon, L. Alibabaei, M. K. Gish, C. J. Dares, D. L. Ashford, R. L. House, G. J. Meyer, J. M. Papanikolas and T. J. Meyer, J. Am. Chem. Soc., 2016, 138, 13085-13102.

26. M. Wang, Y. Yang, J. Shen, J. Jiang and L. Sun, Sustainable Energy Fuels, 2017, 1, 1641.

27. . Chem. Eur. J., 2016, 22, 5261

28.

29.

30.

31.

32.

33.

34.

35.

36.

6. Moya, N. Kemnade, M. R. Osorio, A. Cherevan, D. Granados, D. Eder and J. J. Vilatela, J. Mater. Chem. A, 2017, 5, 24695.

37. F. Jiang, Gunawan, T. Harada, Y. Kuang, T. Minegishi, K. Domen and S. Ikeda, J. Am. Chem. Soc., 2015, 137, 13691.

38. F. Lin, D. Wang, Z. Jiang, Y. Ma, J. Li, R. Li, C. Li, Energy Environ. Sci. 2015, 5, 6400.

39. P. Bornoz, F. F. Abdi, S. D. Tilley, B. Dam, R. van de Krol, M. Graetzel, K. Sivula, J. Phys. Chem. C. 2014, 118, 16959.

40. K. S. Joya, N. Morlanés, E. Maloney, V. Rodionov, K. Takanabe, Chem. Commun. 2015, 51, 13481.

41. W. Li, S. W. Sheehan, D. He, Y. He, X. Yao, R. L. Grimm, G. W. Brudvig, D. Wang, Angew. Chem. Int. Ed. 2015, 54, 11428.

42. B. Liu, J. Li, H.-L. Wu, W.-Q. Liu, X. Jiang, Z.-J. Li, B. Chen, C.H. Tung, L.-Z. Wu, ACS Appl. Mater. Interfaces 2016, 8 , 18577. 
"This document is the Accepted Manuscript version of a Published Work that appeared in final form in Sustainable Energy Fuels, copyright (C) The Royal Society of Chemistry 2018 after peer review and technical editing by the publisher. To access the final edited and published work see:

https://pubs.rsc.org/en/content/articlelanding/2018/se/c8se00146d\#!divAbstract

Table of Contents

\section{$2 \mathrm{H}_{2} \mathrm{O}+\mathrm{hv} \longrightarrow \mathrm{O}_{2}+4 \mathrm{H}^{+}+4 \mathrm{e}^{-}$}

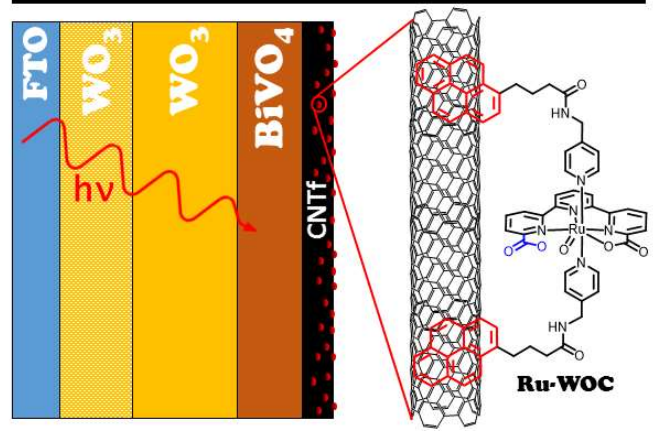

